\title{
Compared Morphology of the Cephalic Musculature in Five Species of Genus Urotrygon (Chondrichthyes: Urolophidae)
}

\author{
Morfología Comparada de la Musculatura Cefálica de Cinco \\ Especies del Género Urotrygon (Chondrichthyes: Urolophidae)
}

Mónica González Isáis* \& Héctor Marcos Montes Domínguez*

GONZÁLEZ, I. M. \& MONTES, D. H. M. Compared morphology of the cephalic musculature in five species of genus Urotrygon (Chondrichthyes: Urolophidae). Int. J. Morphol., 34(1):7-12, 2016.

SUMMARY: This work aims to describe the morphology of dorsal and ventral cephalic musculature in five species of genus Urotrygon. Muscular differences were observed, mainly in the development level. Muscles showing certain degree of variation in the dorsal region were the cucullaris and the ethmoideo-parethmoidalis. In ventral view, higher variation was observed. Muscles showing differences were the depressor rostri, the depressor hyomandibularis, the preorbitalis medial, the coracohioideus, and the depressor mandibularis. Urotrygon aspidurus was the species with the largest differences, as it has no mandibular depressor, and the rostral depressor is quite developed. The shape and arrangement of cephalic musculature in Urotrygon is similar to that reported for genus Urolophus and Dasyatis, however, it is different from that of most specialized myliobatoids.

KEY WORDS: Elasmobranchii, Batoidei, Urotrygon, cephalic musculature.

\section{INTRODUCTION}

The Myliobatoidei suborder includes more than 150 species distributed worldwide (Nelson, 2006). Among myliobatoids is the family Urolophidae, which is the second largest taxon among Myliobatoidei, including about 35 species distributed in tropical and subtropical waters in the Atlantic, Indic and Pacific oceans (Miyake, 1988; Nelson). Most of them inhabit continental sand banks, but some species can be found below the continental slope, even up to $700 \mathrm{~m}$. All species are bethic, and often spend long periods partially buried in soft bottoms. Urolophids are placented viviparous finishing their development in the uterus, with litters of 2-4 organisms. Their gestation period is around three months (Miyake; Nelson; Last \& Stevens, 1994; McEachran \& Notarbartolo di Sciara, 1995).

The muscles of the head and gill skeleton in batoids are more complex than in any other elasmobranchii. They also show a significant variation, mainly in the ventral cephalic region, which is the most widely known.

The works on batoids musculature has focused on anatomical descriptions (De Andrés et al., 1997; Miyake; Nishida, 1990; Miyake et al., 1992; González-Isáis, 2003; González-Isáis \& Montes, 2004; Montes \& González-Isáis,
2007), muscular kinematics (Wilga \& Motta, 1998), and evolutionary feeding mechanism musculature (Dean \& Motta, 2004); some phylogeny studies based on external morphology use characters from the cephalic musculature (Nishida, 1990; McEachran et al., 1996; Lovejoy, 1996; González-Isáis \& Domínguez). The objective of this work was to describe the anatomy of the cephalic dorsal and ventral musculature of five species of the genus Urotrygon, as a basis for future phylogenetic genus research.

\section{MATERIAL AND METHOD}

Five species of the Urotrygon genus were considered in this work: Urotrygon aspidurus, U. chilensis, U. mundus, $U$. nana and $U$. rogersi. Organisms were collected as accompanying fauna in the Pacific Ocean coasts, using dragnets in shrimp boats. The specimens were fixed in formaldehyde $10 \%$, to be later transported to the laboratory. Dissections were conducted with conventional techniques, focusing on the dorsal and ventral cranial musculature for the anatomical description (Fig. 1). For each muscle the following characteristics were analyzed: form, disposition, fiber 
orientation, origin, and insertion. The terminology used herein is based on De Andre's et al., Nishida, Miyake et al. and Wilga \& Motta.

\section{RESULTS}

\section{Dorsal Cephalic Muscles (Fig. 1).}

Ethmoideo-parethmoidalis muscle (EPE): originates on the anterior part of the neurocranium, at the level of the anterior foramen of the preorbital channel, running posteriorly along the internal margin of the propterygium, inserting on its internal margin.

Levator hyomandibularis $(\mathrm{LH})$ : originates on the lateral wall of the neurocranium in the otic region, and runs anterolaterally inserting in the caudal part of the hyomandibular cartilage.
Cucullaris (CC): originates in the anterodorsal face of the scapulocoracoid cartilage, running medially, inserting on one side of the dorsal longitudinal bundle, on a cartilage process of the scapulocoracoid cartilage.

Epiaxialis (EP): paired muscle originated on the anterodorsal face of the scapulacoracoid cartilage, running parallel to the synarcual, inserting on the otic capsules behind the endolymphatic foramina.

Constrictor hyoideus dorsalis (CHD): this muscle originates on the dorsal superficial branchial constrictor 1 and runs anteroventrally, until it inserts in a septum located between the CHD and the constrictor hyoideus ventralis.

Dorsal superficial branchial constrictor muscles (DRSUPC): these are five pairs, and membranes among them are both the origin and the insertion point of each muscle, running anteriorly from its origin.

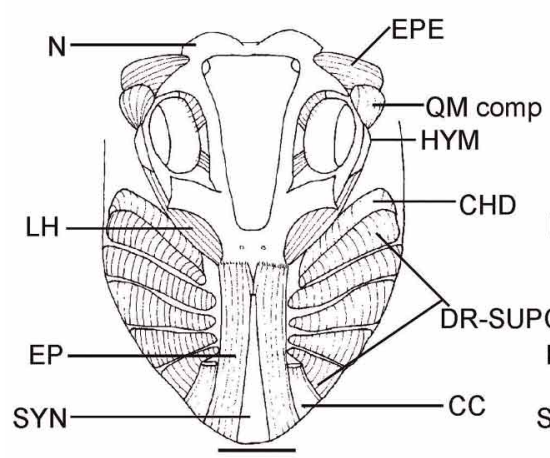

(a)

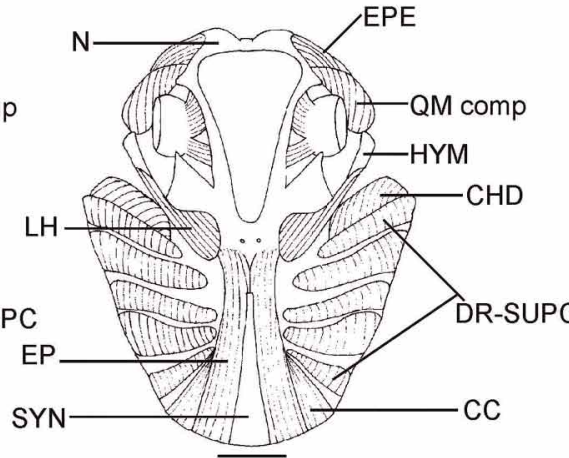

(b)

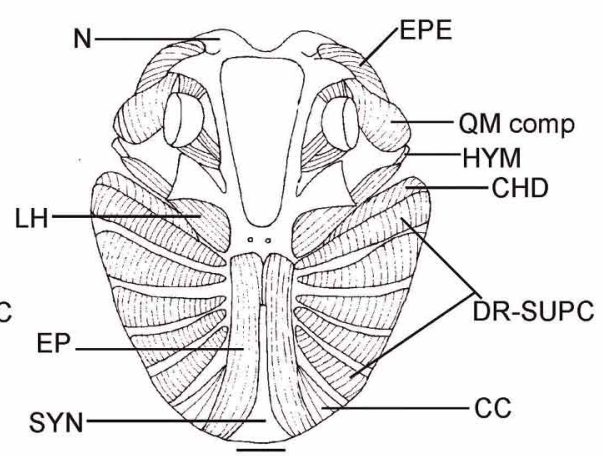

(c)

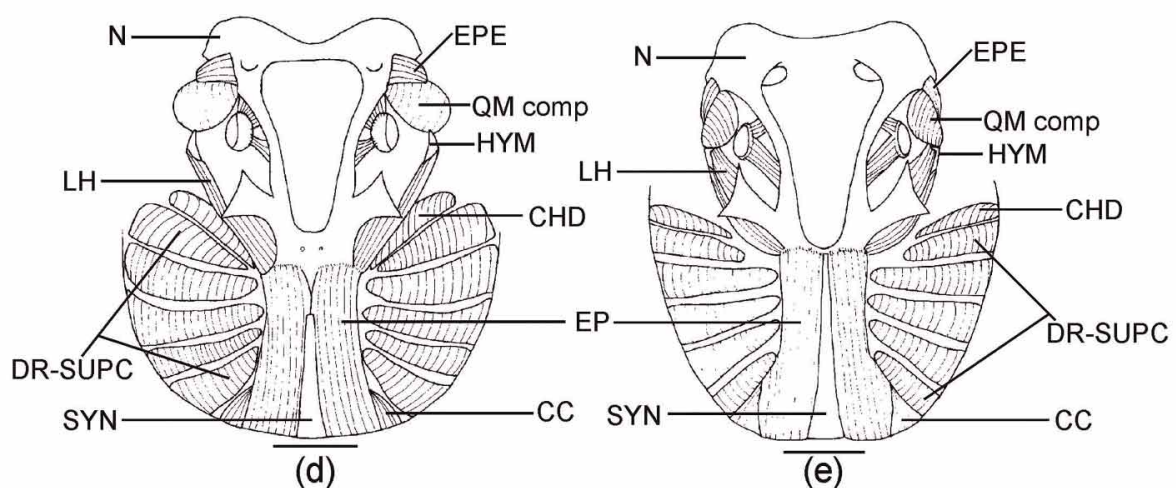

Fig. 1. Dorsal view of the cephalic musculature: (a) Urotrygon chilensis, (b) Urotrygon rogersi, (c) Urotrygon aspidurus, (d) Urotrygon nana and (e) Urotrygon mundus. CC, cucullaris; CHD, constrictor hyoideus dorsalis; DR-SUPC, dorsal superficial branchial constrictor muscles; EP, epiaxialis; EPE, ethmoideo-parethmoidalis; HYM, hyomandibula; LH, levator hyomadibularis; N, neurocranium; QM comp, anterior/posterior quadratomandibularis complex; SYN, synarcual. Scale $=10 \mathrm{~mm}$. 


\section{Ventral cephalic muscle (Figs. 2 and 3)}

Depressor rostri (DR): thin muscle originated in the medium region, wide and elongated anterolaterally, until inserting with an aponeurosis. Some fibers are inserted in the nasal capsules and other in the propterygium.

Depressor hyomandibulae (DHYM): originates on a membrane covering the cephalic part of the coracomandibularis muscles, runs laterodorsally on the caudal part of the mandibular complex, until inserting in the ventral part of the hyomandibular cartilage.
Depressor mandibularis (DM): This muscle was described by Nishida as posterior intermandibularis, it originates on the superficial hyobranchial rafe, on the depressor hyomandibulae muscle; runs anterolaterally and inserts with an aponeurosis on the lateral-caudal rim of Meckel's cartilage.

Coracomandibularis (CM): this is a paired muscle, originating on the deep hypobranchial rafe, runs in cephalic direction, and inserts on the ventral surface of Meckel's cartilage. Fibers of this muscle are long, with parallel arrangement.
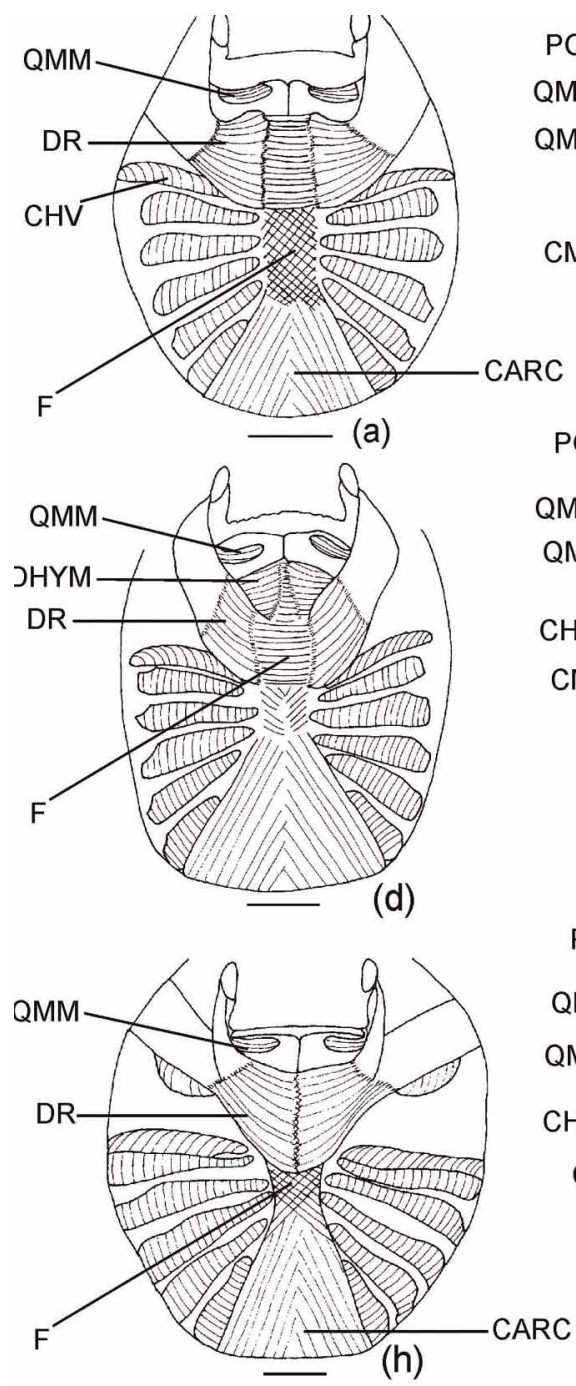

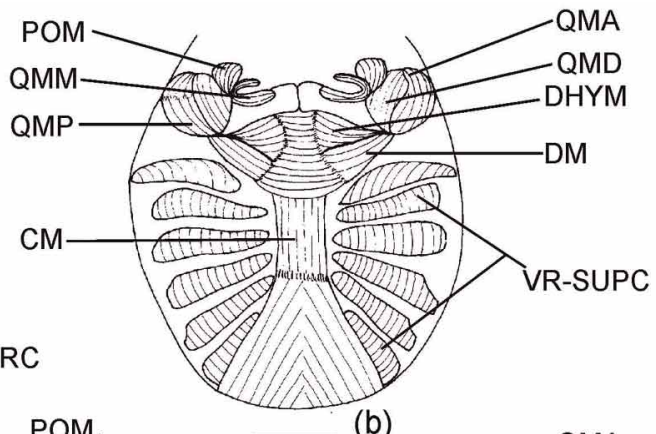

(b)

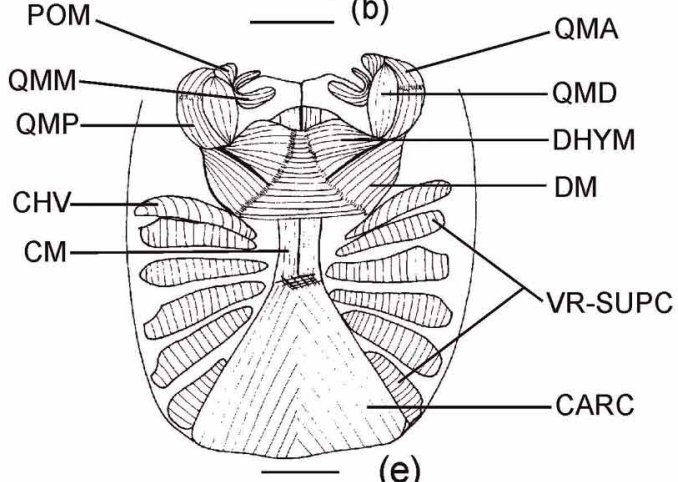

(e)

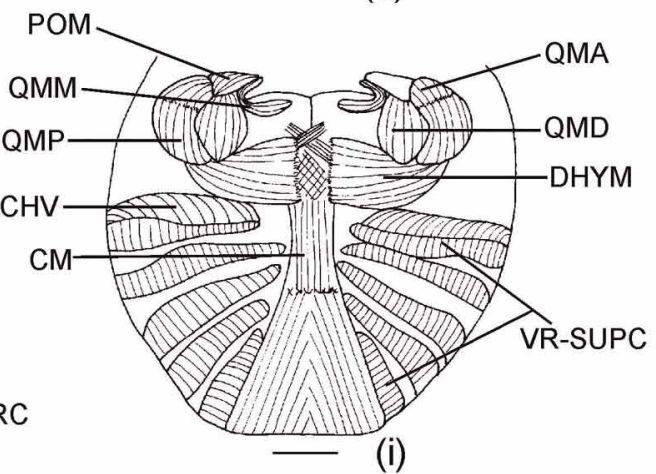

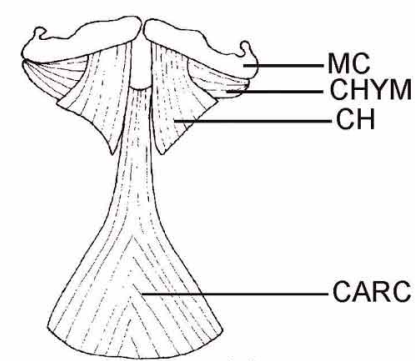

(c)
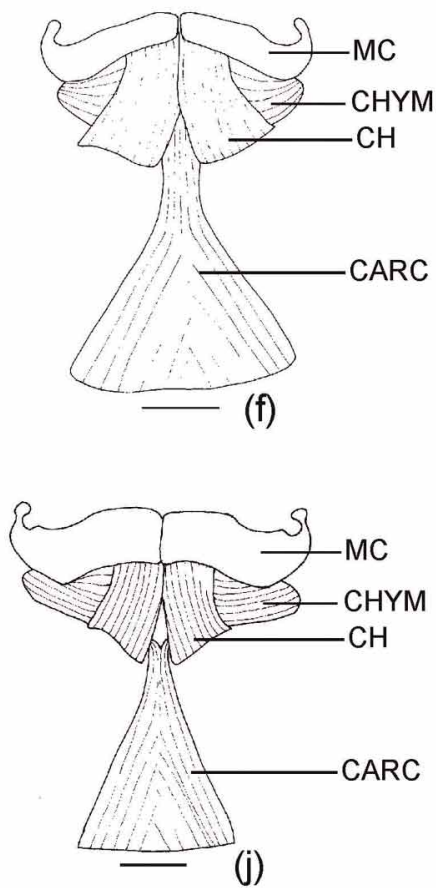

Fig. 2. Ventral view of the cephalic musculature in Urotrygon chilensis: (a) level 1, (b) level 2, and (c) level 3; Urotrygon rogersi: (d) level 1, (e) level 2, and (f); Urotrygon aspidurus: (g) level 1, (h) level 2, and (i). CARC, coracoarcualis; CH, coracohyoideus; CHV, ventral hyoid constrictor; CHYM, coracohyomandibularis; CM, coracomandibularis; DHYM, depressor hyomandibularis; DM, depressor mandibularis; DR, depressor rostri; F, fascia; MC, Meckelian cartilage; POM, preorbitalis medial; QMA, quadratomandibularis anterior; QMD, quadratomandibularis deep; QMM, quadratomandibularis medialis; QMP, quadratomandibularis posterior; VR-SUPC, ventral superficial branchial constrictor muscles. Scale $=10 \mathrm{~mm}$ 
Coracoarcualis (CARC): it originates on the pectoral girdle and runs anteriorly until inserting in a membrane at the level of the constrictor ventral 4.

Coracohioideus $(\mathrm{CH})$ : is a paired muscle located in medial position, originated in a membrane located on the first interbranchial septum, and runs anteriorly until inserting in the hypobranchial 1 , on a thick membrane just below the caudal edge of mandibular cartilage.

Coracohyomandibularis (CHYM): was originated on the medium line and runs anterolaterally, inserting on the caudal edge of mandibular cartilage

Ventral hyoid constrictor $(\mathrm{CHV})$ : originates on interbranchial septum 1, runs dorsally forming the anterior wall of the branchial region, inserting on the membrane separating it from the dorsal hyoid constrictor.

Ventral superficial branchial constrictor muscles (VRSUPC): five pairs, membranes among them are both the origin and the insertion surface of each muscle, running anteriorly from its origin.
Mandibular Complex: it is integrated by muscles anterior, posterior, medium and deep quadratomandibularis and the medial preorbitalis.

Quadratomandibularis anterior (QMA) and posterior (QMP): both muscles form a bundle considerable large. The anterior part (QMA) originates in the palatoquadrate cartilage, fibers run caudally, and the posterior part (QMP) inserts in mandibular cartilage..

Quadratomandibularis deep (QMD): its fibers originate in the palatoquadrate cartilage, run caudally until inserting on mandibular cartilage.

Preorbitalis medial (POM): originates in the palatoquadrate cartilage, and runs caudally until inserting in the anterior part of the deep quadratomandibularis.

Quadratomandibularis medialis (QMM): small paired digastrics muscle originating in the ventral part of Meckel's cartilage, near the symphysis, surrounds the mandible in anterolateral position to form the corner of the mouth, inserting on the ventral side of the palatoquadrate cartilage.

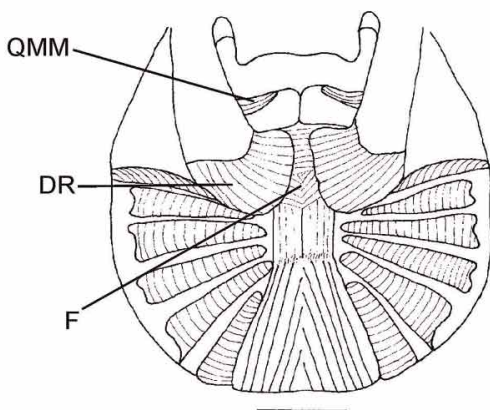

(a)

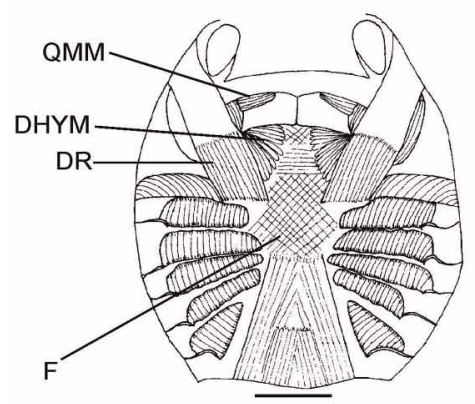

(d)

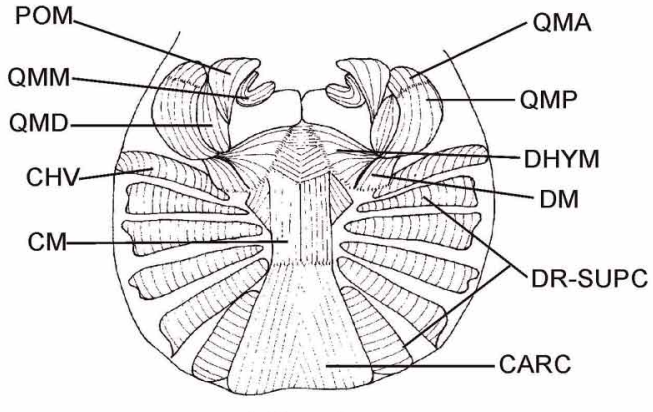

(b)

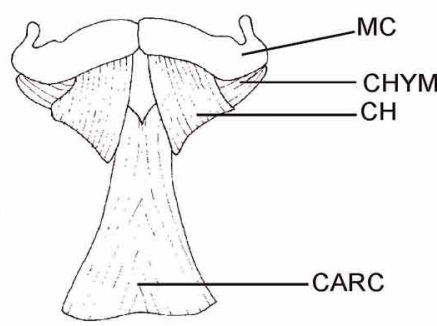

(c)

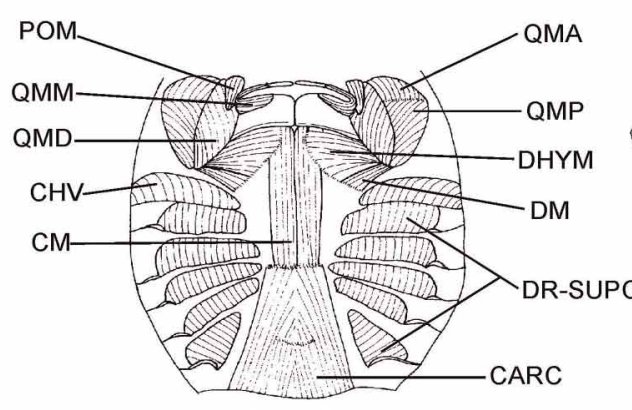

(e)

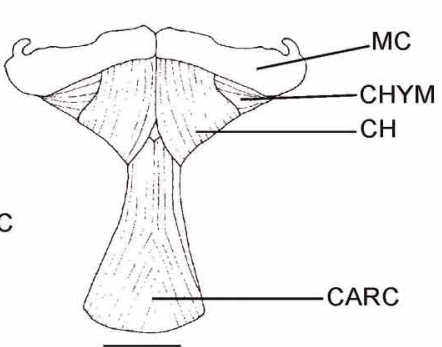

(f)

Fig. 3. Ventral view of the cephalic musculature in Urotrygon nana: (a) level 1, (b) level 2, and (c) level 3; Urotrygon mundus: (d) level 1, (e) level 2, and (f). CARC, coracoarcualis; $\mathrm{CH}$, coracohyoideus; CHV, ventral hyoid constrictor; CHYM, coracohyomandibularis; CM, coracomandibularis; DHYM, depressor hyomandibularis; DM, depressor mandibularis; DR, depressor rostri; F, fascia; MC, Meckelian cartilage; POM, preorbitalis medial; QMA, quadratomandibularis anterior; QMD, quadratomandibularis deep; QMM, quadratomandibularis medialis; QMP, quadratomandibularis posterior; VR-SUPC, ventral superficial branchial constrictor muscles. Scale $=10 \mathrm{~mm}$ 


\section{DISCUSSION}

Urotrygon species studies have the same muscles, excepting the depressor mandibularis, which is absent in Urotrygon aspidurus (Fig. 2h). Variations were observed in the muscle development degree. Two main differences were observed in the dorsal cephalic musculature: 1) Ethmoideoparethmoidalis muscle (EPE): is more developed in Urotrygon chilensis and U. aspidurus (Fig. 1a, c); it has a medium size in $U$. rogersi (Fig. 1b) and is less developed in Urotrygon nana and Urotrygon mundus (Fig. 1d, e). 2) Cucullaris (CC) muscle: it is less developed Urotrygon nana and Urotrygon mundus (Fig. 1d, e).

Main differences in the ventral cephalic muscles were: 1) the depressor rostri (DR) in Urotrygon aspidurus is paired, big and each muscle joins its antimere in the medium region; in the rest of the species is less developed, and the right muscle does not meet its antimere in the medium region. 2) Fibers of the depressor hyomandibularis (DHYM) in U. aspidurus (Fig. 2h) are horizontally oriented, while in other species they form an aigrette. The muscle is more developed in $U$. aspidurus. 3) The preorbitalis medial (POM) is more developed in $U$. aspidurus and U. nana (Fig. 2h, 3b). 4) The depressor mandibularis was not observed in $U$. aspidurus; and is more developed Uortrygon rogersi (Fig. 2e). 5) The coracohioideus is paired, in $U$. aspidurus, $U$. rogersi and $U$. mudus, the right muscle meets with its antimere in the anterior region (Fig. 2f, i, 3f); in U. chilensis and $U$. nana, right and left muscles never get in contact (Figs. 2c and 3c).

Dorsal and ventral cephalic morphology of species of the Urotrygon genus studies have certain variation, mainly in the muscle development degree. Their musculature in dorsal view is similar to that reported by Nishida for Dasyatis izuensis. However, in the latter, the ethmoideoparethmoidalis muscle is not very developed, and in the cucullaris, fibers have a transversal arrangement, which is longitudinal in Urotrygon, additionally, the muscle is smaller in D. izuensis. In ventral view, the musculature is similar to the one reported by Nishida for Urolophus maculatus. The ventral cephalic musculature has important differences when compared to that reported for more specialized myliobatoids (González-Isáis \& Montes; González-Isáis \& Domínguez; Montes \& González-Isáis).

GONZÁLEZ, I. M. \& MONTES, D. H. M. Morfología comparada de la musculatura cefálica de cinco especies del género Urotrygon (Chondrichthyes: Urolophidae). Int. J. Morphol., 34(1):7-12, 2016.

RESUMEN: El presente trabajo tiene por objetivo describir la morfología de la musculatura cefálica dorsal y ventral de cinco especies del género Urotrygon. En los músculos de la región cefálica dorsal y ventral se observaron diferencias, principalmente en el grado de desarrollo. Los músculos que mostraron cierto grado de variación en la región dorsal fueron el cucularis y el etmoideo paraetmoidal. En vista ventral los músculos que mostraron diferencias fueron el depresor rostral, el depresor hiomandibular, el preorbitalis medial, el coracohioideus y el depresor mandibular. Urotrygon aspidurus fue la especie que mostró mayores diferencias ya que no presenta el músculo depresor mandibular, y el depresor rostral está muy desarrollado. La forma y disposición de la musculatura cefálica de Urotrygon es similar a la reportada para especies de los géneros Urolophus y Dasyatis, sin embargo, es diferente a la de los miliobatoideos más especializados.

PALABRAS CLAVE: Elasmobranchii; Batoidei; Urotrygon; Musculatura cefálica.

\section{REFERENCES}

De Andrés, A.; García, G. J. M. \& Muñoz-Chápuli, R. Ventral musculature in elasmobranchs: some functional and phylogenetic implications. In: Proceedings of the Fifth Congress of European Ichthyologists. Stockholm, Department of Vertebrate Zoology, Swedish Museum of Natural History, 1987.

Dean, M. N. \& Motta, P. J. Anatomy and functional morphology of the feeding apparatus of the lesser electric ray, Narcine brasiliensis (Elasmobranchii: Batoidea). J. Morphol., 262(1):462-83, 2004.
González-Isáis, M. Anatomical comparison of the cephalic musculature of some members of the superfamily Myliobatoidea (chondrichthyes): implications for evolutionary understanding. Anat. Rec. A Discov. Mol. Cell Evol. Biol., 271(1):259-72, 2003.

González-Isáis, M. \& Montes, D. H. Comparative anatomy of the superfamily Myliobatoidea (Chondrichthyes) with some comments on phylogeny. J. Morphol., 262(1):51735, 2004. 
Last, P. R. \& Stevens, J. D. Sharks and Rays of Australia. Australia, CSIRO, 1994.

Lovejoy, N. R. Systematics of myliobatoid elasmobranchs: with emphasis on the phylogeny and historical biogeography of neotropical freshwater stingrays (Potamotrygonidae: Rajiformes). Zool. J. Linn. Soc., 117:207-57, 1996.

McEachran, J. D.; Miyake, T. \& Dunn, K. A. Interrelationships of the batoid fishes (Chondrichthyes: Batoidea). In: Stiassny, M. L. J.; Parenti, L. R. \& Johnson, G. D.; Eds. Interrelationships of fishes. San Diego, Academic Press, 1996.

McEachran, J. D. \& Notarbartolo di Sciara, G. Peces Batoideos. In: Fischer, W.; Krupp, F.; Schneider, F.; Summer, C.; Carpenter, K. E. \& Niem, V. H. (Eds.). Guía FAO para la identificación de especies para los fines de la pesca. Pacífico centro-oriental. Vol. 2. Vertebrados. Parte 1. Roma, FAO, 1995.

Miyake, T. The Systematics of the stingray genus Urotrygon with comments of the interrelationships within Urolophidae (Chondrichthyes, Myliobatiformes). Unpublished Ph. D. Dissertation. Texas, Texas A \& M University, College Station, 1988.

Miyake, T.; McEachran, J. D. \& Hall, B. K. Edgeworth's legacy of cranial muscle development with an analysis of muscles in the ventral gill arch region of batoid fiches (Chondrichthyes: Batoidea). J. Morphol., 212(3):213-56, 1992.

Montes, D. H. M. \& González-Isáis, M. Contribution to the knowledge of anatomy of species of genus Mobula Rafinesque 1810 (Chondrichthyes: Mobulinae). Anat. Rec., 290(7):920931, 2007.

Nelson, J. S. Fishes of the World. $4 \mathrm{t}^{\mathrm{h}}$ ed. New York, John Wiley \& Sons, 2006.

Nishida, K. Phylogeny of the suborder Myliobatoidei. Mem. Fac. Fish. Hokkaido Univ., 37(1-2):1-108, 1990.

Wilga, C. D. \& Motta, P. J. Feeding mechanism of the atlantic guitarfish rhinobatos lentiginosus: modulation of kinematic and motor activit. J. Exp. Biol., 201(Pt. 23):3167-84, 1998.
Correspondence to:

Dra. Mónica González Isáis

Prof. Tit. "B" TC

Laboratorio de Anatomía Animal Comparada

Facultad de Estudios Superiores Iztacala

Universidad Nacional Autónoma de México (UNAM)

Los Reyes Iztacala, Tlalnepantla

Estado de México

MEXICO

Email: monigi@unam.mx

Received: 30-04-2015

Accepted: 05-11-2015 